\title{
Psychological Treatments That Cause Harm
}

\author{
Scott O. Lilienfeld \\ Emory University
}

\begin{abstract}
The phrase primum non nocere ("first, do no harm") is a well-accepted credo of the medical and mental health professions. Although emerging data indicate that several psychological treatments may produce harm in significant numbers of individuals, psychologists have until recently paid little attention to the problem of hazardous treatments. I critically evaluate and update earlier conclusions regarding deterioration effects in psychotherapy, outline methodological obstacles standing in the way of identifying potentially harmful therapies (PHTs), provide a provisional list of PHTs, discuss the implications of PHTs for clinical science and practice, and delineate fruitful areas for further research on PHTs. A heightened emphasis on PHTs should narrow the scientist-practitioner gap and safeguard mental health consumers against harm. Moreover, the literature on PHTs may provide insight into underlying mechanisms of change that cut across many domains of psychotherapy. The field of psychology should prioritize its efforts toward identifying PHTs and place greater emphasis on potentially dangerous than on empirically supported therapies.
\end{abstract}

The phrase primum non nocere- "first, do no harm"-captures the essence of the physician's familiar Hippocratic Oath. The Ethics Code of the American Psychological Association (APA) features a similar injunction: Psychologists "take reasonable steps to avoid harming their clients/patients" (APA, 2002, p. 1065; see also p. 1062).

Despite these admonitions, the field of clinical psychology has until fairly recently shown little concern with the problem of harmful treatments (Rhule, 2005). For example, Bergin and Garfield's authoritative and remarkably comprehensive Handbook of Psychotherapy and Behavior Therapy (Lambert, 2003), which psychologists have ranked as the premier book on psychotherapy (Boisvert \& Faust, 2003), contains approximately

Address correspondence to Scott O. Lilienfeld, Department of Psychology, Room 206, Emory University, 532 Kilgo Circle, Atlanta, GA 30322, e-mail: slilien@emory.edu.
2.5 pages (out of a total of 821 pages of text) on the topic of adverse effects in therapy. The recent APA position paper on evidence-based practice (APA Presidential Task Force on Evidence-based Practice, 2006) does not even mention explicitly the problem of potentially harmful psychotherapies. Moreover, the assessment of indicators of failing treatment has until recently received little attention (Mash \& Hunsley, 1993; but see Lambert et al., 2003, for a notable exception).

This state of relative neglect concerning harmful psychological treatments contrasts sharply with the marked recent scientific and media interest ${ }^{2}$ in the potential negative effects (e.g., suicidality) of psychotropic medications, particularly fluoxetine (Prozac) and other selective serotonin reuptake inhibitors (Sharp \& Chapman, 2004). Psychology, of course, has no formal equivalent of medicine's Food and Drug Administration (FDA) to conduct Phase I or Phase II trials, both of which help to identify safety problems with novel treatments before they are disseminated to the public. As a consequence, the systematic monitoring of unsafe psychological interventions devolves largely or entirely to the profession of psychology itself. I will argue that because the field of psychology has been reluctant to police itself (Meehl, 1993), the consequences for mental health consumers and the profession at large have been problematic.

This article represents an effort to focus attention on an undeservedly neglected topic of inestimable scientific and pragmatic importance. Specifically, in this article, I review the current scientific status of potentially harmful therapies (PHTs), identify methodological obstacles to identifying PHTs, offer a provisional list of PHTs, outline the implications of PHTs for clinical practice and research, and delineate fruitful directions for further investigation on PHTs.

\section{THE EFFICACY OF PSYCHOTHERAPY}

Some might maintain that concern with harmful treatments is largely unnecessary given the overwhelming evidence for the efficacy of psychotherapy. Indeed, meta-analyses consistently demonstrate that the positive effects of psychotherapy exceed those of no treatment or placebo treatments for a wide range of conditions, including mood disorders, anxiety disorders, sexual 
dysfunction, bulimia, and insomnia (Westen, Novotny, \& Thompson-Brenner, 2004). At least when posed as a simple and perhaps overly simplistic question concerning statistical main effects, psychotherapy clearly "works" (Dawes, 1994).

\section{Empirically Supported Therapies (ESTs)}

The accumulating data on the efficacy of psychotherapies for specific conditions have been a primary impetus underlying the recent movement toward ESTs. ESTs are lists of treatments that have been found in controlled trials or systematic single-case designs to be efficacious for specific disorders, such as major depressive disorder, panic disorder, obsessive-compulsive disorder, and bulimia (Chambless \& Hollon, 1998).

In the eyes of many psychotherapy scholars, the EST movement has helped to place the field of psychotherapy on firmer scientific footing (Barlow, 2004; Chambless \& Ollendick, 2001). Nevertheless, ESTs remain controversial (Arkowitz \& Lilienfeld, 2006), with some critics maintaining that they are based on an inadequate research foundation (Westen, Novotny, \& Thompson-Brenner, 2004) and that they unduly restrict clinicians' freedom to administer promising interventions that have been insufficiently researched (Bohart, 2000).

\section{The Dodo Bird Verdict}

Most meta-analyses show that, with some exceptions, well-established psychotherapies tend be approximately equivalent in efficacy (Wampold, Mondin, Moody, Stich, Benson, \& Ahn, 1997). This finding has been termed the Dodo Bird verdict, after the Dodo Bird in Alice and Wonderland, who declared following a race that "Everyone has won, and all must have prizes." In its extreme form, the Dodo Bird verdict implies that the therapeutic modalities selected by practitioners for adult disorders (e.g., behavioral, cognitive, psychodynamic) are essentially irrelevant; the variance in psychotherapy outcomes is almost entirely a function of therapist-specific variables (e.g., warmth, genuineness), client-specific variables (e.g., psychological-mindedness, stress reactivity), and their interaction (Wampold, 2001). Indeed, some have argued that lists of ESTs are unnecessary given that virtually all psychotherapies work about equally well (Lundeen, 2005).

Yet emerging findings from the psychotherapy outcome literature demonstrate that not all therapies are equally efficacious. For example, behavioral therapies, such as exposure and response prevention, tend to be more efficacious than nonbehavioral therapies for obsessive-compulsive disorder, generalized anxiety disorder, and specific phobia, as well as for most childhood disorders (Chambless \& Ollendick, 2001; Hunsley \& DiGuilio, 2002). More disconcertingly, recent evidence-much of it emerging only over the past decade-suggests that certain psychological treatments can produce harm in a nontrivial number of individuals (Beutler, Bongar, \& Shurkin, 1998; Lambert \& Miller, 2001; Rhule, 2005).

\section{Reasons Why Harmful Treatments Are Important}

There are two major reasons why all psychotherapy researchers and practitioners should be concerned about PHTs.

First, as noted in the APA (2002) Ethics Code, all clinicians are obliged to avoid procedures that place clients at undue risk of deterioration. Knowledge regarding PHTs can help psychotherapists to avoid harming their clients inadvertently through well-intentioned but deleterious interventions. Moreover, even psychotherapists who do not administer PHTs will surely encounter at least some clients who seek out PHTs as adjunctive treatments. By learning more about PHTs, these clinicians can help their clients to make more informed decisions about which treatments to approach with caution or avoid entirely.

Second, research on the harmful effects of treatment can provide valuable leads regarding the mediators (mechanisms) underlying client deterioration in psychotherapy. Some of these mechanisms, such as premature termination of exposure to anxiety-provoking stimuli or vicarious modeling of maladaptive behavior (see "Mediators" section), may operate even in psychotherapies that are typically efficacious. As a consequence, these mechanisms may contribute to either short-term client deterioration or slower overall client progress even in treatments that generally produce improvement. A better understanding of these mechanisms may therefore yield insights into the sources of unanticipated roadblocks in psychotherapy.

\section{HARMFUL EFFECTS IN PSYCHOTHERAPY: EARLIER CONCLUSIONS}

The possibility of treatment-induced deterioration among psychiatric patients was first observed nearly 7 decades ago (Masserman \& Carmichael, 1938) and has been noted by a number of authors since then (e.g., Stuart, 1970). Over the past several decades, two lines of evidence have traditionally been invoked to buttress the assertion that psychotherapy can sometimes be harmful: (a) deterioration effects and (b) negative effect sizes from meta-analyses of psychotherapy outcome. Neither line of evidence is as straightforward as is often claimed.

\section{Deterioration Effects}

First, the psychotherapy outcome literature on deterioration effects suggests that a relatively small but nontrivial minority of clients, with estimates often ranging from 3 to $6 \%$ or 5 to $10 \%$, become worse following psychotherapy (Mohr, 1995; Strupp, Hadley, \& Gomez-Schwartz, 1977). In the substance abuse treatment literature, the estimates of client deterioration have generally been on the high end of this range, averaging about $10 \%$ or even 15\% (Ilgen \& Moos, 2005; Moos, 2005). Indeed, an international survey of 12 leading psychotherapy outcome 
researchers revealed strong agreement (a mean of 5.7 on a 7point scale) with the assertion, "Approximately $10 \%$ of clients get worse as a result of therapy" (Boisvert \& Faust, 2003).

Nevertheless, the percentages of deterioration effects generated by psychotherapy outcome studies are potentially misleading, as they are too broad in some respects and too narrow in others. As a consequence, they can result in an overestimation of certain harmful effects and an underestimation of others. These percentages are too broad because they may include clients whose deterioration was unrelated to psychotherapy; such clients might have become worse even without treatment. By regarding these percentages as evidence for therapy-induced deterioration, numerous authors in this literature have committed the post hoc ergo proper hoc ("after this, therefore because of this") fallacy (see Friedman, 2006, for a recent example in the popular press). The percentages of deterioration derived from psychotherapy outcome studies are also too narrow because they may miss clients who improved following therapy but who would have improved even more had they not received therapy. In such cases, therapy may have produced harm by slowing the pace of naturally occurring improvement.

The most valid estimates of deterioration effects can be obtained from comparisons of randomly assigned treatment and no-treatment groups (Mays \& Franks, 1980). If significantly more clients exhibit lower end-state functioning following therapy than following no treatment, one can confidently conclude that the deterioration or decelerated rate of improvement was a consequence of therapy. Nevertheless, few good estimates of the prevalence of deterioration effects in psychotherapy are available from such designs.

\section{Negative Effect Sizes in Meta-Analyses}

Second, meta-analyses of treatment outcome consistently reveal negative effect sizes in a notable minority of studies. For example, the seminal Smith, Glass, and Miller (1980) meta-analysis of 475 therapy outcome studies revealed that $9 \%$ of effect sizes were negative. Some subsequent meta-analyses revealed comparable or perhaps slightly higher percentages of negative effect sizes (e.g., Shapiro \& Shapiro, 1982), and a meta-analysis of studies of treatments for adolescent behavioral problems indicated that as many as $29 \%$ of effect sizes were negative (Lipsey, 1992; see also McCord, 2003, and Rhule, 2005). These numbers raise the distinct possibility that certain psychotherapies are harmful to some individuals.

Nevertheless, even these percentages are difficult to interpret because they could represent largely random variation around a mean effect size of zero or even around a slightly positive effect size. Given a sufficiently large sample of studies of either ineffective or only minimally effective treatments, one would anticipate a certain proportion of effect sizes to be negative (Weiss et al., 2005). Therefore, findings of harmful effects for specific treatments should be replicated by independent investigative teams to minimize the possibility of chance results. Nevertheless, this desideratum entails complex ethical considerations (see "Independent Replication" below).

\section{IDENTIFYING PHTS: METHODOLOGICAL ISSUES}

A myriad of methodological obstacles stand in the way of identifying PHTs. I discuss several of the most central here.

\section{Increases in Variance}

A treatment may make certain clients better and others worse, thereby increasing the variance of outcomes beyond that in a notreatment control group (May, Tuma, \& Dixon, 1977). In such cases, reliance on group means alone may mask the presence of harmful effects. When a treatment increases the variance in outcomes, the identification of moderators of treatment outcome is necessary to predict who will improve as opposed to deteriorate (or remain unchanged) as a consequence of psychotherapy. Of course, increases in variance do not necessarily reflect negative effects, as they can be produced by efficacious treatments that increase the variance of positive outcomes relative to control treatments.

As a consequence, journal editors should require psychotherapy researchers to report the full ranges of scores on the principal dependent variables, broken down by quartile or some similarly user-friendly metric. For dependent measures that are dichotomous (e.g., a suicide attempt during the course of treatment), journal editors should require researchers to report the "number needed to harm" (i.e., the number of patients one would need to expose to the intervention to obtain one harmful outcome compared with the control intervention; March, Klee, \& Kremer, 2006; Sierra, 2005).

\section{Differences Across Symptom Domains}

Some treatments may make certain symptoms better but others worse. Therefore, negative effects should be examined across multiple symptom domains. When a treatment is associated with improvements in some symptom domains but worsening in others, clinicians must carefully consider the cost-benefit ratio of this intervention and discuss the potential risks of deterioration with their clients. The issues here are not easily resolved and often require a consideration of client values and preferences in addition to scientific evidence (APA Task Force on Evidence-Based Practice, 2006).

Moreover, decrements in functioning following treatment may be reported by some individuals but not others, underscoring the importance of obtaining outcome data from diverse informants (Mash \& Hunsley, 1993). For example, classic research on encounter-group "casualties" suggests that group members perceive deterioration that therapist leaders do not (Yalom \& Lieberman, 1971). 


\section{Multiple Forms of Harm}

On a related note, the harmful effects of psychotherapy are almost certainly multidimensional. They include symptom worsening, the appearance of new symptoms, heightened concern regarding extant symptoms, excessive dependency on therapists, reluctance to seek future treatment (Boisvert, 2003), and even physical harm (Mercer, Sarner, \& Rosa, 2003). Hence, the assessment of treatment failures should incorporate multiple domains of the individuals' functioning, not merely deterioration in target symptoms (Mash \& Hunsley, 1993).

\section{Harm to Relatives or Friends}

Some treatments may produce harm in the relatives or friends of clients in addition to, or instead of, clients themselves. For example, some treatments that are otherwise innocuous or even effective with clients could produce a heightened risk of false abuse allegations against family members. As a consequence, the largely ubiquitous equation of harmful treatments with iatrogenic (meaning doctor-induced) treatments in the psychotherapy deterioration literature is problematic, as the latter term typically refers only to negative effects in clients.

The inclusion of harm to others in a definition of therapy-induced harm implies the need to consider extrascientific factors, such as value judgments concerning the appropriate goals of psychotherapy. For example, if a specific type of individual psychotherapy targeted for individuals with marital distress tends to produce improvements in clients but increased distress in the spouses of clients, should this side effect of treatment be considered harmful? Moreover, in marital therapy, separation or even divorce can arguably be a desirable outcome when both partners are experiencing extreme marital distress. As a consequence, the very definition of a harmful effect may be influenced by value-laden considerations that lie outside the scope of this article. The issues here are again not readily resolved and hinge on often-unarticulated a priori assumptions regarding what types of change are more or less desirable. These complexities underscore the need for psychotherapy researchers to report the full scope of outcomes so that readers can draw their own conclusions regarding the presence of harmful effects.

\section{Short-Term Versus Long-Term Deterioration}

Some treatments may make clients worse in the short term yet prove efficacious in the long term. For example, a minority (perhaps 10-20\%) of clients with posttraumatic stress disorder (PTSD) display clear evidence of transient symptom exacerbation following the introduction of exposure treatment. Nevertheless, these individuals go on to improve at the same rate as clients who do not exhibit exacerbation (Foa, Zoellner, Feeny, Hembree, \& Alvarez-Conrad, 2002; Tarrier et al., 1999). Moreover, some efficacious marital therapies produce timelimited increases in marital conflict and distress early in treatment (Hunsley \& Lee, 1995).
Nevertheless, one must be careful not to conclude from these findings that "clients must get worse before they can get better." Indeed, this claim has sometimes been advanced by proponents of PHTs as a rationalization for failing treatments (see Lilienfeld \& Lynn, 2003). Although certain efficacious treatments, especially those that teach clients to confront previously avoided stimuli or conflicts, sometimes produce increases in anxiety in initial sessions, there is no evidence that this is the case for all efficacious treatments. Therefore, clinicians should be skeptical of treatments that produce early increases in anxiety that do not habituate.

In addition, one may suspect that some ESTs could be PHTs if administered improperly. For example, many standard texts warn that an insufficient duration of exposure and response prevention-that is, termination of exposure before adequate habituation of anxiety has occurred - may result in a worsening of clients' anxiety symptoms, although systematic data on this issue are scant (Shipley \& Boudewyns, 1980; Stone \& Borkovec, 1975).

\section{Client Drop-Out}

Psychotherapies that are harmful may yield high rates of premature client termination (drop-outs). The causes of premature termination are heterogeneous. In certain cases, drop-out is attributable to financial exigencies, personal changes (e.g., moves to other states), or other variables unrelated to the efficacy of therapy. Nevertheless, in other cases client drop-out appears to be related to either especially successful or unsuccessful treatment. Some clients who drop out of therapy have improved quickly and no longer perceive a need for therapy, whereas others have deteriorated and are dissatisfied with treatment (Garfield, 1994; Tehrani, Krussel, Borg, \& Munk-Jorgensen, 1996). Moreover, weak therapeutic alliance is sometimes a predictor of client drop-out (Beckham, 1992), and a weak alliance itself can be an indicator or byproduct of failing therapy. As a consequence, studies that compare only therapy completers (using "on treatment analyses") in treatment versus no-treatment groups may underestimate the prevalence of harmful effects.

In studies with nontrivial drop-out rates, therapy outcome investigators must therefore conduct analyses that account for missing data, which sometimes result from client deterioration. Several statistical methods for addressing missing data are available, including (a) multiple imputation and (b) "intent-totreat" analyses, which include all patients randomized to treatment and control groups. Intent-to-treat analyses, in turn, can be based on either last-observation-carried-forward analyses, which treat the final measurement from each patient as the final observation on that individual, or noncompleter-equals-failure analyses, which treat therapy drop-outs as failures (Gilden, 1998). None of these approaches yields the most veridical estimate of 
client deterioration, as each hinges on its own set of assumptions regarding the causes of client drop-outs.

\section{Independent Replication}

As noted earlier, preliminary findings that certain therapies produce harmful effects should be interpreted with caution pending replication by independent investigative teams. Nevertheless, ethical issues present serious obstacles to replicating iatrogenic effects, because researchers may understandably be reluctant to conduct further studies on therapies that have been found to be potentially iatrogenic in initial studies. Moreover, it may often be unethical to randomly assign clients to treatments that pose a significant risk of harm.

Therefore, the requirement for independent replication puts investigators in an ethical bind. If they attempt to replicate previous findings of iatrogenic effects, they place clients at risk for harm; if they do not attempt to replicate such findings, they leave researchers, practitioners, and mental health consumers uncertain of how to interpret initial reports of iatrogenic effects.

There is no straightforward solution to this dilemma other than to encourage researchers who have adventitiously identified iatrogenic effects in their investigators to report them fully. There are no good estimates of the magnitude of the file-drawer effect (Rosenthal, 1979) in the literature on the iatrogenic effects of psychotherapy. In contrast to the traditional use of this term in psychology, the file-drawer effect in this body of research refers to the tendency of investigators to selectively withhold (i.e., not publish) studies or selected study findings yielding results opposite to the predicted direction, as opposed to merely null results. Some statisticians have referred to significant findings that run opposite to the predicted direction as Type III errors (Leventhal \& Huynh, 1996). Enrolling all intervention studies in a centralized data bank that is publicly accessible (McCord, 2003; Rhule, 2005) would be a partial solution to the possible underreporting of Type III errors, as this data bank would increase the likelihood that all relevant results from these studies are reported. Moreover, journals should require full access to all outcome data from psychotherapy outcome trials, not merely the portion of outcome data that has been published.

\section{Strength of Evidence}

The strength of evidence concerning harmful treatments varies markedly across investigations. We can rank order the evidence for harmful therapeutic effects along a hierarchy of evidentiary certainty, with the most definitive evidence deriving from randomized controlled trials (RCTs), less definitive evidence deriving from quasi-experimental studies using matched comparison groups, and still less definitive evidence deriving from naturalistic designs or multiple case reports (see Ghaemi \& Hsu, 2005). Nevertheless, when low-base-rate negative events (e.g., false allegations of severe sexual abuse, initial emergence of "alter" personalities, initial onset of panic attacks) consist- ently appear shortly after the introduction of treatment, such evidence should be accorded considerable weight even when it does not derive from RCTs.

\section{Identifying and Operationalizing PHTs}

To identify PHTs, I conducted a search of the PsycINFO database using the terms psychotherapy, therapy, and treatment, on the one hand, and harmful, harm, iatrogenic, worse, and deterioration, on the other. In addition, I consulted major published reviews of psychotherapy deterioration effects (e.g., Mohr, 1995; Rhule, 2005; Strupp et al., 1977; Werch \& Owen, 2002). Because none of these reviews attempted to provide a list of PHTs or classify PHTs in terms of levels of evidence for harm, the present article goes well beyond previous narrative reviews of dangerous treatments.

I operationalize treatments as PHTs if they fulfill the following three conjunctive criteria:

1. They have demonstrated harmful psychological or physical effects in clients or others (e.g., relatives)

2. The harmful effects are enduring and do not merely reflect a short-term exacerbation of symptoms during treatment

3. The harmful effects have been replicated by independent investigative teams

For criterion 1, I define psychological harm as including not only deterioration but also a decelerated rate of improvement that is a consequence of psychotherapy.

I have limited the definition of harm to include only relatively direct effects of treatment. Treatments that are by themselves ineffective but innocuous can produce harm indirectly, most notably by exacting "opportunity costs" such as lost time and the energy and effort expended in seeking out interventions that are not beneficial (Lilienfeld, 2002). Moreover, opportunity costs may preclude clients from obtaining efficacious interventions. Hence, one should bear in mind that a wide variety of psychological treatments can produce significant indirect harm. The dangers generated by opportunity costs should not be underestimated. For example, a client with a specific phobia who forgoes flooding or systematic desensitization (both of which have been found to be efficacious for this condition; Barlow, 2001) in favor of insight-oriented therapies, which have not been found to be efficacious for specific phobia, may endure years or even decades of needless anxiety. Indeed, Williams, Turner, and Peer (1985) reported that some clients with acrophobia (severe fear of heights) who had sought out suboptimal treatments had tolerated several decades of disabling anxiety symptoms, only to be treated successfully in less than $3 \mathrm{hr}$ of exposure-based therapy.

Nevertheless, all ineffective or even effective-but-suboptimal treatments can generate opportunity costs. As a consequence, incorporating opportunity costs into a definition of harmful treatments would result in the inclusion of all treatments that are 
TABLE 1

Provisional List of Potentially Harmful Therapies

\begin{tabular}{|c|c|c|}
\hline Intervention & Potential harm & Primary source of evidence \\
\hline & Level I (probably harmful for some individuals) & \\
\hline Critical incident stress debriefing & $\begin{array}{l}\text { Heightened risk for posttraumatic stress } \\
\text { symptoms }\end{array}$ & RCTs \\
\hline Scared Straight interventions & Exacerbation of conduct problems & RCTs \\
\hline Facilitated communication & $\begin{array}{l}\text { False accusations of child abuse against family } \\
\text { members }\end{array}$ & Low base rate events in replicated case reports \\
\hline Attachment therapies (e.g., rebirthing) & Death and serious injury to children & Low base rate events in replicated case reports \\
\hline Recovered-memory techniques & Production of false memories of trauma & Low base rate events in replicated case reports \\
\hline DID-oriented therapy & Induction of "alter" personalities & Low base rate events in replicated case reports \\
\hline $\begin{array}{l}\text { Grief counseling for individuals with normal } \\
\text { bereavement reactions }\end{array}$ & Increases in depressive symptoms & Meta-analysis \\
\hline Expressive-experiential therapies & Exacerbation of painful emotions & RCTs \\
\hline Boot-camp interventions for conduct disorder & Exacerbation of conduct problems & Meta-analysis \\
\hline \multirow[t]{2}{*}{ DARE programs } & $\begin{array}{l}\text { Increased intake of alcohol and other } \\
\text { substances (e.g., cigarettes) }\end{array}$ & RCTs \\
\hline & Level II (possibly harmful for some individuals) & \\
\hline Peer-group interventions for conduct disorder & Exacerbation of conduct problems & Quasi-experimental studies \\
\hline Relaxation treatments for panic-prone patients & Induction of panic attacks & Replicated single-case designs \\
\hline
\end{tabular}

Note. $\mathrm{RCTs}=$ randomized controlled trials; DID $=$ dissociative-identity disorder; DARE $=$ drog abuse and resistance education.

less efficacious than the most efficacious treatment, rather than treatments that produce negative effects. As a consequence, I have excluded such treatments from the list of PHTs satisfying my definition of harm.

Moreover, some treatments may not be on the provisional list of PHTs because they have not been adequately investigated. As a consequence, a treatment's absence from the provisional PHT list does not necessarily imply its safety. For example, there are preliminary indications that (a) certain self-help programs (Rosen, 1987); (b) court-mandated treatment for spouse abusers (Feder \& Wilson, 2005); (c) psychodynamic treatments for schizophrenia (Mueser \& Berenbaum, 1990); (d) school-based prevention programs for antisocial behaviors, such as school counseling that is not cognitive-behavioral in nature (Wilson, Gottfredson, \& Najaka, 2001); and (e) home-based psychosocial nursing-visitation programs for individuals recuperating from heart attacks (Frasure-Smith et al., 1997; Frasure-Smith, Lesperance, Gravel, Masson, Juneau, \& Bourassa, 2002) produce harmful effects in at least some individuals. Nevertheless, these findings should be regarded as tentative given the absence of independent replication in controlled studies.

Finally, in delineating PHTs, I have excluded somatic treatments for psychological disorders, including psychopharmacological interventions. Nevertheless, in doing so, I do not intend to minimize the hazards posed by certain somatic interventions. For example, chelation therapy and hyperbaric oxygen therapy for autism and other developmental disabilities may carry significant risks of physical harm (Herbert, Sharp, \& Gaudiano, 2002; Levy \& Hyman, 2005; Romanczyk, Arnstein, Soorya, \& Gillis, 2003).
In accord with the hierarchy of evidentiary certainty outlined earlier, I have grouped PHTs into two broad and admittedly coarse "levels" on the basis of the strength of evidence for harmful effects: (a) those that probably produce harm in some clients and (b) those that possibly produce harm in some clients (see Table 1). In distinguishing between these two levels, I have placed particular weight on three factors: (a) the internal validity of studies (see Ghaemi \& Hsu, 2005), (b) the replication of findings by independent investigators, and (c) the appearance of new symptoms shortly following the introduction of psychotherapy.

Specifically, I have placed PHTs into Level 1 (probable harm) if the evidence for harm derives from (a) RCTs that have been replicated by at least one independent investigative team, (b) meta-analyses of RCTs, or (c) the consistent and sudden emergence of low-base-rate adverse events following the introduction of therapy. I have placed PHTs into Level 2 (possible harm) if the evidence from harm derives from (a) quasi-experimental designs that have been replicated by at least one independent investigative team or (b) replicated single-case designs. Nevertheless, readers should understand that the distinction between these two levels is preliminary given the current state of the research literature.

The list of PHTs offered here is intended to be provisional and open to revision. Indeed, one can expect this list to evolve over time following constructive criticism from psychotherapy researchers and clinicians, and with the addition of new treatment outcome data. Nor is this list necessarily exhaustive given that certain investigations may have yielded unexpected harmful effects (Type III errors) that went unreported by the authors. 
Nevertheless, this list represents an initial effort in the peerreviewed psychological literature to provide a systematic taxonomy of PHTs (see also Lilienfeld, Fowler, Lohr, \& Lynn, 2005, for a preliminary list). I refer to these treatments as "potentially" harmful for two reasons: (a) The evidence of harmful effects for some treatments on this list is highly suggestive but not definitive, and (b) it is unlikely that any of the treatments on this list are harmful for all individuals exposed to them.

\section{A PROVISIONAL LIST OF PHTs}

\section{Level I: Treatments That Probably Produce Harm in Some Individuals}

\section{Critical Incident Stress Debriefing (CISD)}

CISD is designed to prevent symptoms of PTSD and related anxiety disorders among individuals exposed to extreme stressors. It is typically a single-session procedure that lasts 3 to $4 \mathrm{hr}$, although it is occasionally conducted across several sessions. CISD is usually performed in groups and administered within 24 to $72 \mathrm{hr}$ of the traumatic event (Lohr, Hooke, Gist, \& Tolin, 2003). CISD therapists (a) strongly encourage group members to discuss and "process" their negative emotions, (b) delineate the PTSD symptoms that group members are likely to experience, and (c) discourage members from discontinuing participation once the session has begun.

Litz, Gray, Bryant, and Adler's (2002) meta-analysis of RCTs of CISD versus no treatment or alternative-treatment control conditions yielded an overall effect size of $d=-.11$ for PTSD symptoms. Several controlled studies indicate that CISD is ineffective in warding off PTSD symptoms in trauma-exposed individuals.

Moreover, two RCTs suggest that CISD has harmful long-term effects, perhaps by impeding natural recovery processes (see McNally, Bryant, \& Ehlers, 2003; Rose, Bisson, \& Wessely, 2001, for reviews). Bisson, Jenkins, Alexander, and Bannister (1997) found that burn victims randomly assigned to CISD evidenced significantly higher PTSD and overall anxiety symptoms at a 13-month follow-up than did burn victims randomly assigned to an assessment-only control group. Mayou, Ehlers, and Hobbs (2000) performed a 3-year follow-up from an RCT of victims of motor-vehicle accidents. Individuals who received CISD exhibited significantly higher levels of global psychopathology and travel anxiety, but not PTSD symptoms per se, than did individuals in an assessment-only control group. A third RCT by Sijbrandij, Olff, Reitsma, Carlier, and Gersons (2006) examined the effects of CISD on trauma-exposed individuals at 2 -week, 6 -week, and 6-month follow-ups. The authors found that CISD produced no significant effects on PTSD symptoms compared with a control condition at any of the three time points. Nevertheless, at the 6-week follow-up period only, individuals with high baseline levels of hyperarousal exhibited significantly more PTSD symptoms following CISD relative to the control condition. Because this subgroup analysis was performed on a post-hoc basis and revealed evidence of harm at only one time point, it should be interpreted with caution.

Interestingly, most recipients of CISD report that they found it helpful even when objective indices reveal otherwise (Carlier, Lamberts, von Uchelen, \& Gersons, 1998; McNally et al., 2003). This paradox is most parsimoniously explained by two facts: (a) Most clients randomly assigned to CISD groups, like most trauma-exposed individuals, tend to improve on their own accord, and (b) the evidence from RCTs suggests that these clients would probably have improved even more without treatment. As a consequence, clients who have received CISD may misattribute naturally occurring improvement to the intervention.

\section{"Scared Straight" Programs}

Scared Straight programs attempt to frighten at-risk adolescents away from a life of future crime by exposing them to the harsh realities of prison life. These programs began in the early 1970s in New Jersey and became popular following a highly publicized documentary in 1979. In 1982, an RCT examining the initial New Jersey program revealed that the Scared Straight condition resulted in a significant increase in arrests compared with a notreatment control condition. Researchers reported similar results with "kids spend the day in prison" programs (Lipsey, 1992). A recent meta-analytic review of seven randomized and controlled quasi-experimental studies of Scared Straight Programs demonstrated that these interventions increased the odds of offending by a ratio of between 1.6 and 1.7 to 1 (Petrosino, Turpin-Petrosino, \& Buehler, 2003).

\section{Facilitated Communication (FC)}

FC is premised on the notion that autistic children's communication defects are attributable primarily to motor, not cognitive, problems (Biklen, 1990). Hence, with the aid of a facilitator who offers resistance to the child's hands, children with autism and with other serious developmental disabilities can ostensibly produce communications using a computer keyboard. Nevertheless, carefully controlled studies conclusively demonstrate that the "facilitated communications" purportedly produced by autistic children are unknowingly generated by facilitators themselves, who are unintentionally guiding autistic children's hands over the keyboard (Herbert, Sharp, \& Gaudiano, 2002; Romanczyk et al., 2003).

FC has been associated with at least five dozen allegations of child sexual abuse against the parents of autistic children, the substantial majority of which have never been corroborated (Jacobson, Mulick, \& Schwartz, 1995). In these cases, the facilitated communications were ostensibly generated by facilitators themselves, who may have either suspected familial abuse or harbored implicit causal theories about a link between early abuse and subsequent autism. Nevertheless, it is not known whether FC generates more false abuse allegations than other 
suggestive techniques (e.g., repeated questioning and prompting of children) for unearthing abuse (Botash et al., 1994).

\section{Attachment Therapies}

Attachment therapists maintain that separation from biological parents often produces enduring adverse effects, including intense anger, in children. This rage, attachment therapists maintain, must be released for children to achieve adaptive functioning. The techniques used by these therapists are sometimes intrusive and aggressive and can include verbal abuse and physical restraint. One variant of attachment therapy, holding therapy, requires therapists or caregivers to physically hold children until they look into the adult's eyes. Another worrisome version of attachment therapy, rebirthing, is based on the notion that the birth trauma can generate unprocessed rage that must be released by reenacting this trauma.

During rebirthing sessions, therapists may wrap children in blankets, sit on them, and squeeze them repeatedly in an effort to simulate the birth process. Several children, including 10-yearold Candace Newmaker in Colorado in 2000, have been suffocated to death during rebirthing sessions (Mercer et al., 2003). No RCTs have been conducted to determine whether rebirthing, holding, or other attachment therapies yield any positive effects for childhood behavioral problems (Mercer, 2002).

\section{Recovered-Memory Techniques}

Although data from controlled studies are lacking, there is considerable evidence that suggestive therapeutic methods, such as repeated therapist prompting of memories, hypnosis, and guided imagery, can produce subjectively compelling but false memories in some individuals (Lynn, Lock, Loftus, Krackow, \& Lilienfeld, 2003). Specifically, there are numerous reports of adult clients reporting histories of childhood sexual abuse, satanic ritual abuse, and even alien abductions for the first time following the introduction of recovered-memory methods. The finding that recovered-memory techniques can yield memories of alien abductions (Clancy, 2005) and even past-life child abuse appears to provide an "existence proof" that at least some of the memories generated by these methods are false.

Moreover, there is reason to believe that such memories can be deleterious to both clients and their family members. Data from recovered-memory legal claims filed in Washington State reveals that suicidal ideation increased nearly seven-fold and that psychiatric hospitalizations increased over five-fold over the course of therapy (see Dineen, 2001). Nevertheless, because these data derive from uncontrolled studies and unrepresentative samples marked by selection bias (e.g., legal involvement), the true degree of harm generated by recovered-memory methods is difficult to estimate. Moreover, recovered-memory cases have been associated with thousands, perhaps tens of thousands, of uncorroborated allegations against close family members (Australian Psychological Society, n.d.).
The question of whether certain recovered memories of trauma are genuine remains unresolved. It is at present unclear whether recovered-memory techniques unearth at least some genuine memories in addition to creating false ones (e.g., Schooler, Ambadar, \& Bendikson, 1997; but see Loftus \& Guyer, 2002). Nevertheless, there appears to be little disagreement that such techniques are associated with false-memory production in at least some individuals (Lynn et al., 2003).

Dissociative Identity Disorder (DID)-Oriented Psychotherapy Proponents of DID-oriented therapy believe that patients with DID, known formerly as multiple personality disorder, harbor latent indwelling identities ("alters") that must be brought to light for treatment to progress successfully. Many DID alters are associated with self-injurious behavior, suicide attempts, and verbal and physical aggression toward others (American Psychiatric Association, 2000). Moreover, many of these behaviors are specific to only one alter (Putnam, Guroff, Silberman, Barban, \& Post, 1986). Although the extant data are strictly correlational, there is reason to suspect that the presence of alters can impede treatment progress. In one study of DID patients in treatment, the number of alters correlated significantly $(r=.48)$ with the length of time to "fusion," that is, the reintegration of alters into a "single" personality (Coons, 1984).

Many advocates of DID-oriented therapy use suggestive methods, including prompting and contacting purported alters through hypnosis, introducing alters to one another, and mapping out the interrelations among alters (Spanos, 1994). Some also attempt to recover memories of childhood sexual or physical abuse, which many DID-oriented therapists believe to be a strong risk factor for DID (but see Lilienfeld \& Lynn, 2003, and Lilienfeld et al., 1999, for challenges to this claim). At least one prominent DID-oriented therapist advocates the use of a "bulletin board" in which DID alters can post written messages to one another (Putnam, 1989); another prominent DID-oriented therapist encourages the use of "inner board meetings" as "a good way to map the system [of alters], resolve issues, and recover memories" (Ross, 1997, p. 351). These and other suggestive techniques are prevalent in the DID treatment community (see Piper, 1997, pp. 61-68).

There are numerous reasons to believe that these techniques can create alters in addition to, or perhaps instead of, discovering them. Only about $20 \%$ of DID patients exhibit clear-cut alters prior to treatment, and full-blown alters emerge in the remaining $80 \%$ only following psychotherapy (Kluft, 1991). Moreover, the number of alters tends to increase over the course of DID-oriented therapy (Piper, 1997; Ross, Norton, \& Wozney, 1989).

Although DID-oriented therapists typically claim that these findings reflect the discovery rather than creation of alters, multiple lines of converging evidence suggest that many and perhaps most alters are products of inadvertent therapist suggestion (Lilienfeld \& Lynn, 2003). For example, most diagnoses 
of DID derive from a relatively small number of therapists, most of whom are DID specialists (Mai, 1995); therapists who use hypnosis tend to have more DID patients in their caseloads than therapists who do not use hypnosis (Powell \& Gee, 1999); and laboratory studies indicate that nonclinical participants provided with appropriate cues can readily reproduce the core features of DID (Spanos, Weekes, \& Bertrand, 1985).

\section{Grief Counseling for Normal Bereavement}

Studies of grief therapy for individuals who have suffered losses of loved ones suggest the possibility of harmful effects, at least among those experiencing relatively normal bereavement reactions.

Neimeyer (2000) reported the results of a meta-analysis of 23 RCTs of grief therapy. He found a mean effect size of $d=.13$, which, although low, differed significantly from zero. Nevertheless, grief counseling appeared to increase the variance in outcomes among clients relative to no treatment. Specifically, Neimeyer (2000) found that $38 \%$ of clients who received grief therapy would have achieved superior end-state functioning had they been assigned to the no-treatment control condition, suggesting the distinct possibility of iatrogenic effects among a sizeable subset of individuals exposed to grief counseling. These effects appeared to be most marked among individuals who experienced "normal" as opposed to "traumatic" grief reactions, with the latter operationalized as reactions to deaths that were sudden or unexpected or in which grief was long lasting. Specifically, the percentages of deteriorated clients (those who showed worse functioning following therapy than at the outset of therapy) approached $50 \%$ in the former group but were only $17 \%$ in the latter group. Considerably more research is needed to identify moderators of treatment effects in grief counseling.

\section{Expressive-Experiential Psychotherapies}

Research suggests that although expressive-experiential psychotherapies (e.g., focused expressive psychotherapy, Daldrup, Beutler, Engle, \& Greenberg, 1988; gestalt therapy, Perls, 1969), which focus on releasing and experiencing powerful affects, can be helpful for some clients, such therapies may result in deterioration for others (Mohr, 1995). Two RCTs revealed that clients exposed to expressive-experiential therapies exhibited higher rates of deterioration than did those in either no-treatment (Beutler, Frank, Schieber, Calvert, \& Gaines, 1984) or alternative-treatment conditions (Mohr et al., 1990). Because the latter study did not contain a no-treatment control group, however, conclusions regarding therapy-induced deterioration must be viewed cautiously. Moreover, although in the latter study the percentage of deterioration in patients assigned to an expressive-experiential (gestalt) group was higher (19\%) than that in patients assigned to a cognitive-therapy group (5\%), it was identical to the deterioration in patients assigned to a selfhelp book group (19\%).
The possibility of harm resulting from experiential-expressive therapies accords with results from psychotherapy-analogue studies suggesting that releasing pent-up anger often engenders increased hostility (Lewis \& Bucher, 1992). More broadly, these results dovetail with research demonstrating that emotional catharsis, especially when not accompanied by a constructive cognitive restructuring of troubling situations, often backfires to produce heightened long-term negative emotions (Littrell, 1998).

\section{Boot Camp Interventions for Conduct Disorder}

Like Scared Straight programs, military-style boot camps were widely promoted as a cost-effective "get tough" approach for antisocial adolescents. These programs emphasize discipline, obedience to authority, and acquisition of appropriate social skills. Nevertheless, the evidence concerning the effects of boot camps on criminal recidivism has been exceedingly mixed (Bottcher \& Ezell, 2005; Parent, 2003). A recent meta-analysis of both RCTs and quasi-experimental studies revealed no significant overall effects of boot camps on antisocial behavior. When examined individually, 9 studies showed positive effects (see also Weiss, Wilson, \& Whitemarsh, 2005, for positive findings), 8 showed iatrogenic effects (higher recidivism), and 12 studies showed no significant effects. The meta-analysis did not detect any moderators (e.g., experimental vs. quasi-experimental nature of design; adolescent vs. adult offenders) that could account for these striking discrepancies across studies (MacKenzie, Wilson, \& Kider, 2001).

Boot camps have also been associated with several highly publicized deaths of adolescents (8 charged in teen's boot camp death, 2006), most of which appear to have been a consequence of physical violence or excessive physical restraint. Similarly, wilderness therapy programs, which attempt to teach troubled adolescents coping skills by exposing them to challenging natural environments, have been associated with several deaths due to dehydration, drowning, and other causes (Utah wilderness therapy deaths, 2003). Nevertheless, it is not known whether the death rates in boot camps or wilderness programs exceed those in other treatment programs or in typical detention facilities.

\section{Drug Abuse and Resistance Education (DARE) Programs}

A number of controlled studies of substance-abuse-prevention programs, particularly those targeted at preventing drug use, have shown iatrogenic effects (Werch \& Owen, 2002). The best known and most popular of these programs is DARE, which uses uniformed police officers to teach schoolchildren (a) about the risks of drug use and (b) social skills to resist peer pressure to try drugs. Most research indicates that DARE is largely or entirely ineffective (Lynam et al., 1999; MacKillop, Lisman, Weinstein, \& Rosenbaum, 2003), with many studies yielding null results. Moreover, the results of several RCTs and quasi-experimental studies suggest that DARE and similar programs based on 
resisting social influence may actually increase intake of alcohol and perhaps other drugs (Werch \& Owen, 2002).

\section{Level II: Treatments That Possibly Produce Harm in Some Individuals}

Peer-Group Interventions for Conduct Disorder

Dishion and Andrews (1995) found that adolescents enrolled in peer groups showed higher levels of antisocial behaviors and tobacco than matched adolescents enrolled in parent-focused groups, at 1- and 3-year follow-ups (Dishion, McCord, \& Poulin, 1999). In addition, the results of several quasi-experimental studies suggest that "deviancy training"-that is, the reinforcement of antisocial behavior by group discussions-is associated with significant increases in adolescent externalizing behavior (Dishion, Eddy, Haas, Li, \& Spracklen, 1997). Nevertheless, a recent meta-analysis of quasi-experimental studies of peer-group interventions for conduct problems found little support for iatrogenic effects, with the possible exception of interventions administered in early adolescence (Weiss et al., 2005). The reasons for these marked discrepancies in study outcomes require clarification.

\section{Relaxation Treatments for Panic-Prone Patients}

Small-sample controlled experimental data and numerous case reports suggest that some patients with panic disorder experience paradoxical increases in anxiety and even unexpected panic attacks during relaxation and other procedures characterized by a heightened focus on bodily sensations (Adler, Craske, \& Barlow, 1987; A.S. Cohen, Barlow, \& Blanchard, 1985; Lynn, Martin, \& Frauman, 1996). In one experimental study (Heide \& Borkevec, 1984), substantial percentages of patients with generalized anxiety similarly experienced increases in subjective and physiological tension during either progressive relaxation (31\%) or meditation (54\%). Nevertheless, because no attempts were made to habituate patients to relaxation or meditation by means of prior graded exposure or other procedures, these findings do not demonstrate that relaxation or meditation are inevitably associated with negative effects.

Nevertheless, controlled studies are needed to confirm the occurrence of higher rates of panic and anxiety among patients exposed to relaxation as opposed to no treatment and to determine whether these increases endure beyond therapy sessions. Moreover, there is controlled research evidence that relaxation is often an effective treatment adjunct for individuals with panic disorder, phobias, and other anxiety disorders (Ost, 1987). Therefore, it is likely that relaxation is useful for some anxietydisordered patients but harmful for others.

\section{IMPLICATIONS OF RESEARCH ON PHTS}

Some psychotherapists have assumed that "doing something is always better than doing nothing" and that therapy is at worst innocuous (Lilienfeld, Lynn, \& Lohr, 2003). The literature reviewed here challenges this presumption and provides grounds for concern regarding the continued proliferation of "fad" and "fringe" psychotherapies (Beyerstein, 2001; Singer \& Lalich, 1996). There are well over 500 "brands" of psychotherapy (Eisner, 2000), most of which have not been examined in controlled trials. The literature reviewed here suggests that it would be erroneous to presume that these treatments are safe prior to subjecting them to adequate tests.

\section{Is the Dodo Bird Extinct?}

The finding that some treatments are iatrogenic indicates that the Dodo Bird verdict, at least in its strong form of the null hypothesis of equivalence of all psychotherapies, is untenable, because certain treatments appear to be ineffective and even harmful. In addition to findings of treatment specificity for at least some disorders (e.g., exposure and response prevention for obsessive-compulsive disorder), the results reviewed here are another reason to declare the Dodo Bird extinct (see Beutler, 2002). Why, then, have many previous authors accepted the Dodo Bird verdict as correct? To some extent, it is probably because the magnitude of nonspecific effects (e.g., therapist factors) typically does greatly outweigh specific effects (e.g., therapeutic modality) for most conditions (Wampold, 2001).

Nevertheless, uncritical acceptance of this verdict probably also stems from influential research on "bona fide" psychotherapies, that is, treatments that are already well established and derived from known psychological principles (e.g., Wampold et al., 1997). By restricting meta-analyses to bona fide therapies, such as cognitive, behavioral, interpersonal, humanistic, and short-term psychodynamic treatments, some researchers have almost certainly restricted the range of psychotherapy outcomes and thereby minimized the likelihood of detecting ineffective or even harmful treatments. In essence, the conclusion that can be drawn from these studies is this: When we examine therapies that all appear to be reasonably well accepted or that are based on plausible theoretical premises, the differences among therapies tend to be minimal. Although this conclusion is not itself trivial, it overlooks the crucial point that some widely administered therapies (see "Prevalence" section) are neither widely accepted in the scientific community nor derived from especially plausible theoretical principles. Although typically regarded as fringe psychotherapies within the confines of the Ivory Tower, these "outlier" treatments excluded from some meta-analyses are important from both a scientific and pragmatic perspective.

\section{PHTs Should Come Before ESTs}

The findings reported here also imply that the field's nearly exclusive emphasis on identifying ESTs is misplaced. Some might contend that the EST list should be sufficient to address the problem of PHTs, because clinicians who restrict their 
treatments to ESTs will necessarily avoid PHTs. Nevertheless, surveys of practitioners demonstrate that substantial pluralities or even majorities do not use ESTs or other scientifically based interventions. This appears to be the case even for the treatment of anxiety disorders (e.g., obsessive-compulsive disorder, panic disorder, phobias), for which there is compelling evidence that behavioral and cognitive-behavioral interventions (e.g., exposure and response prevention) are superior to most other interventions (e.g., Freiheit, Vye, Swan, \& Cady, 2004; Goisman, Warshaw, \& Keller, 1999).

The effort to identify ESTs has considerable merit for many purposes. For example, the EST movement has helped to place the field of psychotherapy on more solid scientific footing and has assisted therapists and mental health consumers with the often bewildering task of distinguishing efficacious from inefficacious treatments (Barlow, Levitt, \& Bufka, 1999; Chambless \& Ollendick, 2001; but see Westen et al., 2004, for a demurral). Moreover, a focus on PHTs is in no way inconsistent with the effort to identify and disseminate ESTs to the clinical community, as both efforts can comfortably proceed simultaneously.

Nevertheless, we need not resolve the contentious scientific, conceptual, and pragmatic issues surrounding ESTs to make significant headway in the effort to curtail the use of PHTs. Given the clinician's prime responsibility to do no harm, the effort to identify PHTs is considerably more pressing than the need to identify ESTs and should be accorded higher priority. As already noted, research demonstrates that a broad array of psychotherapies work fairly well for numerous psychological conditions (Wampold et al., 1997). Hence, in effect, much of the contemporary EST movement probably represents an attempt to detect relatively minor differences in efficacy among treatments that are likely to be reasonably safe and effective.

Our field should therefore instead prioritize its efforts toward pinpointing treatments that are demonstrably harmful or ineffective and disseminating this information to current practitioners, students in training, potential clients, managed-care organizations, and the media. In addition, therapists who administer techniques that are associated with a significant risk of harm should be required to explicitly inform their clients of this risk. From the standpoint of the safety of mental health consumers, the lowermost end of the distribution of treatment efficacy is probably more critical than the uppermost end.

Moreover, from a purely pragmatic standpoint, it may be easier to proscribe than to prescribe clinical practices. This approach may also be a more efficient means of safeguarding clients from treatments that can make them worse. That is, asking practitioners to refrain from administering a circumscribed number of harmful or demonstrably ineffective interventions may be a more realistic short-term goal than asking them to effect a sea-change in their long preferred modes of psychotherapy. Indeed, one of the most oft-heard criticisms of the EST movement is its stifling of therapists' freedom and flexibility to administer their favored interventions and to experiment with potentially useful variants of these interventions (Bohart, 2000; Fox, 2000). The merits and demerits of this argument notwithstanding, it seems likely that a heightened emphasis on PHTs relative to ESTs would be more easily and rapidly implemented, as well as more readily embraced by practitioners whose preferred therapeutic modalities (e.g., psychodynamic, humanistic; see Westen, Novotny, \& Thompson-Brenner, 2004) are conspicuously underrepresented on the EST list.

Both proponents and opponents of the EST movement should be able to find common ground on one central point: Treatments that have the potential to produce harm should either be avoided or, in the case of treatments that yield both positive and negative effects, implemented only with caution. A heightened emphasis on PHTs may therefore help to narrow the scientist-practitioner gap (Fox, 1996; Tavris, 2003) by focusing the efforts of both EST proponents and opponents on a significant point of consensusnamely, the ethical injunction to first do no harm.

\section{FUTURE RESEARCH DIRECTIONS}

In many respects, the still-nascent literature on harmful treatments generates more questions than answers. Here, I address five major unresolved questions regarding PHTs.

\section{Prevalence of PHTs}

As noted earlier, few good data on the prevalence of deterioration effects are available from studies comparing treatments with no-treatment control conditions. Similarly, surprisingly few data are available concerning the prevalence of PHTs. Nevertheless, there are ample reasons to believe that at least some PHTs are widely administered, even by therapists with advanced education and training.

For example, surveys of doctoral-level (Ph.D. and Psy.D.) psychotherapists in the mid 1990s indicated that about $25 \%$ regularly use two or more recovered-memory techniques, such as hypnosis and guided imagery, to uncover child sexual abuse in female clients (Polusny \& Folette, 1996; Poole, Lindsay, Memon, \& Bull, 1995). Nevertheless, systematic data on the contemporary use of these methods are lacking. Counselors who administer CISD probably number in the thousands; in the aftermath of the September 11, 2001 terrorist attacks, one CISD firm in Atlanta dispatched therapists to 200 companies in New York City (McNally et al., 2003). FC remains popular in many U.S. communities; professionals are using it with approximately 200 schoolchildren in Whittier, California alone (Rubin \& Rubin, 2005). As of the early to mid 1990s, DARE programs were being implemented in about half of all U.S. local school districts (MacKillop et al., 2003). As of 1996, 48 militarystyle boot camps for behavior-disordered adolescents were operating in 27 states (MacKenzie, Gover, Armstrong, \& Mitchell, 2001). 
Nevertheless, considerably more data are needed to ascertain the prevalence of these and other PHTs, as well as the variables correlated with their use. A comprehensive survey of PHT use in the broader clinical community is sorely needed. For example, it is not known whether the use of PHTs correlates with therapists' level of education (e.g., doctoral vs. master's level) or theoretical orientation (e.g., behavioral vs. humanistic).

Nevertheless, even were these data to demonstrate that PHT use is more widespread among nonpsychologists (e.g., social workers, marital and family counselors, psychiatric nurses, trained paraprofessionals) than among psychologists, such a finding would not absolve psychologists from the responsibility of becoming aware of these treatments and their potential risks. As noted earlier, a number of clients seen by psychologists may seek out PHTs as adjunctive interventions. Moreover, many practicing psychologists may collaborate with or interact with nonpsychologist colleagues who administer PHTs. In addition, such findings would provide a powerful impetus for major professional organizations within psychology, such as the Association for Psychological Science and APA, to establish alliances with organizations in other mental health professions to minimize the administration and dissemination of PHTs.

\section{Reasons for the Continued Popularity of PHTs}

Why do some PHTs remain popular in certain sectors of the clinical community despite evidence for their potentially damaging effects? The answer to this question itself warrants investigation. Most or all of these interventions surely arise from a perceived need within the mental health community, and it is likely that the overwhelming majority of practitioners who administer them do so with the best of intentions.

Nevertheless, social-psychological research on belief perseverance demonstrates that firmly held beliefs can be surprisingly resistant to contradictory evidence (Anderson, Lepper, \& Ross, 1980). Persistent beliefs concerning the efficacy of PHTs may, in turn, be mediated by attributions regarding the causes of client deterioration. For example, the literature on dispositional bias in psychotherapy (e.g., Chen, Froehle, \& Morran, 1997) suggests that individuals may often attribute client deterioration to individual-difference variables even when therapeutic factors are responsible. Moreover, a plethora of variables can lead individuals to be fooled into concluding that useless or even harmful treatments are efficacious (see Beyerstein, 1997, for an article that should be required reading for all clinical and counseling psychology students). In the case of PHTs, it seems plausible that treatments that produce a decelerated pace of improvement, such as CISD, are more likely to deceive observers than are those that produce deterioration, as the former interventions are followed by an alleviation in symptoms. This intriguing possibility should be examined in controlled research.

Moreover, some PHTs may appear to be efficacious because many individuals overestimate the prevalence of negative effects without treatment (see also P. Cohen \& Cohen, 1984, for a discussion of the clinician's illusion). For example, many mental health professionals believe that the majority of individuals exposed to severe trauma develop PTSD, when in fact controlled data indicate that $75 \%$ or more of trauma-exposed individuals typically do not develop PTSD (Sommers \& Satel, 2005). As a result, some practitioners may erroneously attribute the negative effects of CISD, for example, to the effects of trauma rather than to the intervention itself. Many parents and proponents of DARE programs may similarly conclude that these interventions are efficacious because they overestimate the number of children and adolescents who engage in drug abuse (Lynam et al., 1999). Consequently, advocates of DARE may accurately observe that some children and adolescents engage in problematic behaviors following this intervention, but fail to attribute these behaviors to the negative effects of treatment.

\section{Therapist Variables}

It will be important to identify therapist variables that predispose to therapy-induced deterioration and to examine their potential interactions with PHTs. Paralleling findings in the psychotherapy outcome literature for efficacious therapies (Wampold, 2001), therapist variables may turn out to account for considerably more variance than therapeutic modality in treatment-induced deterioration. For example, there are indications that therapists or encounter-group leaders who are charismatic yet highly confrontational and intrusive can place clients at risk for deterioration (Mohr, 1995; Yalom \& Lieberman, 1971). Perhaps not surprisingly, low levels of therapist empathy and warmth, whether rated by clients or therapists themselves, are predictive of client deterioration (Lafferty, Beutler, \& Crago, 1989; Mohr, 1995). As some authors have observed, the identification of potentially harmful therapists may ultimately prove to be even more important than the identification of potentially harmful therapies (C. Boisvert, personal communication, February 2006). Nevertheless, it seems probable that the variance in client deterioration, like the variance in client improvement following efficacious therapies, is attributable to both therapy and therapist effects measured independently. It is not known whether these two sources of variance are additive, multiplicative (interactive), or both, in their influence.

\section{Client Variables}

There are also suggestions that client individual differences, such as high levels of borderline personality disorder traits (Mohr, 1995) and perhaps psychopathic personality traits (Harris, Rice, \& Cormier, 1994; but for a competing view, see D’Silva, Duggan, \& McCarthy, 2004; Skeem, Monahan, \& Mulvey, 2002) sometimes contribute to deterioration. Nevertheless, many of the conclusions commonly drawn from these studies are questionable, because the deterioration observed in clients with high levels of these traits may have occurred even without treatment. To ascertain whether the deterioration among these clients is attributable to psychotherapy, it will be necessary to 
detect replicable statistical interactions between client individual-difference variables and the presence versus absence of treatment. These interactions address the question of whether clients with certain traits become worse as a result of, rather than merely following, psychotherapy.

Moreover, it will be important to examine client variables as potential moderators of PHT outcome, as some PHTs may be harmful for certain clients but not for others. For example, CISD may be especially harmful for clients whose preferred coping strategy is suppression of emotion but less harmful or perhaps even slightly efficacious for clients whose preferred coping strategy is emotional expression. Moreover, relaxation may be especially likely to induce panic attacks in anxiety-prone individuals with high levels of absorption (Tellegen \& Atkinson, 1974), a disposition to become immersed in sensory or imaginative experiences (Lilienfeld, 1997).

\section{Mediators}

Finally, it will be necessary to uncover mediators of harmful effects in psychotherapy (see Bootzin \& Bailey, 2005, for a thoughtful discussion). The identification of such mediators should afford considerable insight into the etiological mechanisms underpinning treatment-induced deterioration. As noted earlier, many of these mediators may operate from time to time, albeit in attenuated form, even in therapies that are generally efficacious. As a consequence, these mediators may help in identifying harmful treatment mechanisms that cut across a broad swath of treatment modalities.

For example, the negative effects of CISD may be attributable to premature termination of exposure to anxiety-provoking stimuli, which may leave many clients more anxious at the end than beginning of sessions. Similar processes may be operative in expressive-experiential therapies, which may encourage some clients to express intensely anxiety-producing affect before they have had the opportunity to habituate to it adequately. Alternatively, the negative effects of CISD may be due to the tendency of therapists to prime trauma-exposed clients to anticipate PTSD symptoms, thereby creating a self-fulfilling prophecy in which clients passively accept symptoms rather than attempt to overcome them (Bootzin \& Bailey, 2005; Sijbrandij et al., 2006; see also Boisvert \& Faust, 2002). The harmful effects of Scared Straight and boot-camp programs may be attributable to juvenile offenders' vicarious exposure to criminal role models, to the increased resentment engendered in them by confrontational interactions, or both. The probable negative effects of some DARE programs on substance abuse intake may be attributable to the inadvertent normalization of the use of relatively mild substances (e.g., alcohol) resulting from an excessive focus on severe substances (e.g., cocaine, heroin; see Rhule, 2005; Werch \& Owen, 2002). Finally, the possible negative effects of relaxation in panic-prone patients may be attributable to increasing these individuals' focus on interoceptive sensations (e.g., breathing) that they misinterpret as symptoms of anxiety (Adler et al., 1987).

As intriguing as these explanations are, they are merely conjectural, because few researchers have examined mediators of harmful effects. The aforementioned list of potential mediators barely scratches the surface of the possible mechanisms underlying therapy-induced deterioration. Nevertheless, further discussion of such mediators would be premature given the absence of controlled investigations that have incorporated measures of potential mediators of deterioration. Investigators who conduct research on PHTs or variants of these interventions should therefore incorporate measures of potential mediators of deterioration. The search for such mediators may help researchers and therapists to better understand the reasons for therapy-induced deterioration and permit them to design novel treatments, or redesign existing treatments, to minimize the risk of harm to clients. Indeed, at least some PHTs might become efficacious treatments following modifications. For example, variants of CISD that incorporate prolonged exposure and ensure adequate habituation to anxiety-provoking imagery might prove to be efficacious, although controlled research is necessary to investigate this possibility.

Moreover, the identification of such mediators may ultimately point researchers in the direction of underlying principles of negative change, such as premature termination of exposure, vicarious exposure to negative role models, and induction of false traumatic memories, that cut across numerous specific techniques (for discussions of overarching principles of therapeutic change, see Castonguay \& Beutler, 2006; Rosen \& Davison, 2003). In the long term, a catalogue of such underlying principles could prove to be more informative and parsimonious than a catalogue of PHTs, although it remains to be seen whether a set of higher-order principles underlying most or all forms of therapy-induced deterioration can be identified.

\section{CONCLUDING THOUGHTS}

In closing, the time has come for clinical researchers and psychotherapists to become more familiar with fringe and fad treatments, including PHTs, at least some of which continue to be administered widely in the clinical community (Beyerstein, 2001; Lilienfeld, 1998; Tavris, 2003). It may be tempting to turn a blind eye to these treatments on the grounds that they do not pass the "smell test" for scientific plausibility and therefore do not merit serious consideration. Nevertheless, the research on potential harm presented here suggests that this complacent attitude is likely to be detrimental to client welfare and to the credibility of mental health professionals.

Because psychology lacks an FDA to ensure safety monitoring and quality control of treatments, the profession at large must be considerably more aggressive in self-policing and in confronting the hazards posed by PHTs. In the recent past, the principal impetus for constraining the use of some PHTs, particularly 
recovered-memory techniques and DID-oriented therapy, has come not from within the psychological profession but rather from outside of it, in the form of widely publicized lawsuits against practitioners (Lynn et al., 2003). Therefore, major professional organizations in psychology should play a more active role in educating clinicians regarding the hazards posed by PHTs. Regrettably, training in some PHTs, including CISD and rebirthing, has been eligible for continuing-education credit from APA (Wood, Garb, Lilienfeld, \& Nezworski, 2002).

Moreover, exposure to research on PHTs and other treatments of questionable efficacy (see Norcross, Koocher, \& Garofalo, 2006) should become a required component of the education and training of mental health professionals, including clinical, counseling, and school psychologists; social workers; counselors; psychiatrists; and psychiatric nurses. Students in training also need to understand that even well-intentioned interventions can sometimes produce harm. Nevertheless, considerably more research is needed to identify PHTs and mediators and moderators of PHT outcome.

The provisional PHT list presented here should be considered a work in progress, to be revised and refined over time. This list should provide helpful signposts to therapists regarding which treatments to avoid or administer only with considerable caution. Nevertheless, this list per se is in many respects less important than the overarching conclusion that should be drawn from it: Some psychological treatments can exert harmful effects on certain individuals. Clinicians must therefore become more vigilant regarding the possibility of therapy-induced harm in their everyday practices.

Fortunately, recent work by Lambert and his colleagues (e.g., see Lambert et al., 2003, for a meta-analysis) points to a partial potential antidote against PHTs. Specifically, this research suggests that (a) tracking client outcomes using standardized questionnaires administered every session and (b) providing prompt feedback to clinicians regarding clients' failure to make expected treatment gains significantly enhance therapeutic efficacy relative to a no-feedback control condition. In addition, such feedback reduces the rates of symptom deterioration by 4 to $8 \%$. Presumably, this warning system permits therapists to make midcourse corrections in treatment that had been generating negative effects. The increasing influence of managed care may make adoption of Lambert's system mandatory in many clinical settings and may help to minimize the risks posed by PHTs.

A number of years ago, an undergraduate in one of my classes asked me, in all earnestness, whether all physicians were still required to take the "Hypocritical Oath." Fortunately, psychologists who implicitly pledge to "do no harm" by embracing the APA (2002) Ethics Code can readily avoid behaving hypocritically in their clinical practice. By becoming aware of research on PHTs and keeping abreast of the still-emerging literature on unsafe psychological interventions, practicing clinicians can aspire to the laudable goals of the Hippocratic Oath and thereby fulfill their solemn mandate to do no harm.
Acknowledgments - The author thanks Hal Arkowitz, Gayle Beck, Charles Boisvert, Joanne Davis, Susan Himes, Glenn Hutchinson, Jeffrey Lohr, William O'Donohue, Harry Reis, John Riolo, Richard Stuart, and several anonymous reviewers for their extremely helpful comments on an earlier draft of this article, and Drew Westen and Jill Littrell for useful suggestions and discussions.

\section{REFERENCES}

Adler, C.M., Craske, M.G., \& Barlow, D.H. (1987). Relaxation-induced panic (RIP): When resting isn't peaceful. Integrative Psychiatry, 5, 94-100.

American Psychiatric Association. (2000). Diagnostic and statistical manual of mental disorders, 4th edition, text revision. Washington, DC: Author

American Psychological Association. (2002). Ethical principles of psychologists and code of conduct. American Psychologist, 57, 1060-1073.

Anderson, C.A., Lepper, M.R., \& Ross, L. (1980). The perseverance of social theories: The role of explanation in the persistence of discredited information. Journal of Personality and Social Psychology, 39, 1037-1049.

APA Presidential Task Force on Evidence-Based Practice (2006). Evidence-based practice in psychology. American Psychologist, 61, 271-285.

Arkowitz, H., \& Lilienfeld, S.O. (2006, April). Psychotherapy on trial. Scientific American Mind, 2, 42-49.

Australian Psychological Society (n.d.). Recovered memory therapy in Australia. Retrieved October 17, 2006, from http://recoveredmemorytherapy.blogspot.com/.

Barlow, D.H. (Ed.). (2001). Clinical handbook of psychological disorders: A step-by-step treatment manual (3rd ed.). New York: Guilford Press.

Barlow, D.H. (2004). Psychological treatments. American Psychologist, $59,869-878$.

Barlow, D.H., Levitt, J.T., \& Bufka, L.F. (1999). The dissemination of empirically supported treatments: A view to the future. Behavior Research and Therapy, 37(Suppl. 1), S147-S162.

Beckham, E.E. (1992). Predicting patient dropout in psychotherapy. Psychotherapy: Theory, Research, Practice, Training, 29, 177182.

Beutler, L.E. (2002). The dodo bird is extinct. Clinical Psychology: Science and Practice, 9, 30-34.

Beutler, L.E., Bongar, B., \& Shurkin, J.L. (1998). Am I crazy or is it my shrink? New York: Oxford University Press.

Beutler, L.E., Frank, M., Schieber, S.C., Calvert, S., \& Gaines, J. (1984). Comparative effects of group psychotherapies in a shortterm inpatient setting: An experience with deterioration effects. Psychiatry, 44, 67-76.

Beyerstein, B.L. (1997). Why do bogus therapies seem to work? Skeptical Inquirer, 29, 29-34.

Beyerstein, B.L. (2001). Fringe psychotherapies: The public at risk. Scientific Review of Alternative Medicine, 5, 70-79.

Biklen, D. (1990). Communication unbound: Autism and praxis. Harvard Educational Review, 60, 291-314.

Bisson, J.L., Jenkins, P.L., Alexander, J., \& Bannister, C. (1997). A randomized controlled trial of psychological debriefing for victims of acute harm. British Journal of Psychiatry, 171, 78-81. 
Bohart, A.C. (2000). Paradigm clash: Empirically supported treatments versus empirically supported psychotherapy practices. Psychotherapy Research, 10, 488-493.

Boisvert, C. (2003). Negative effects in psychotherapy: Research findings and clinical implications. Directions in Clinical and Counseling Psychology, 15, 37-48.

Boisvert, C.M., \& Faust, D. (2002). Iatrogenic symptoms in psychotherapy: A theoretical exploration of the potential impact of labels, language, and belief systems. American Journal of Psychotherapy, 546, 244-259.

Boisvert, C.M., \& Faust, D. (2003). Leading researchers' consensus on psychotherapy research findings: Implications for the teaching and conduct of psychotherapy. Professional Psychology: Research and Practice, 34, 508-513.

Bootzin, R.R., \& Bailey, E.T. (2005). Understanding placebo, nocebo, and iatrogenic treatment effects. Journal of Clinical Psychology, 61, 871-880.

Botash, A.S., Babuts, D., Mitchell, N., O'Hara, M., Lynch, L., \& Manuel, J. (1994). Evaluations of children who have disclosed sexual abuse via facilitated communication. Archives of Pediatric and Adolescent Medicine, 148, 1282-1287.

Bottcher, J., \& Ezell, M.E. (2005). Examining the effectiveness of boot camps: A randomized experiment with a long-term follow-up. Journal of Research in Crime and Delinquency, 42, 309-322.

Carlier, I.V., Lamberts, R.D., Van Uchelen, A.J., \& Gersons, B.P. (1998). Clinical utility of a brief diagnostic test for posttraumatic stress disorder. Psychosomatic Medicine, 60, 42-47.

Castonguay, L.G., \& Beutler, L.E. (2006). Principles of therapeutic change that work. New York: Oxford University Press.

Chambless, D.L., \& Hollon, S. (1998). Defining empirically supported therapies. Journal of Consulting and Clinical Psychology, 66, $7-18$.

Chambless, D.L., \& Ollendick, T.H. (2001). Empirically supported psychological interventions: Controversies and evidence. Annual Review of Psychology, 52, 685-716.

Chen, M.-W., Froehle, T., \& Morran, K. (1997). Deconstructing dispositional bias in clinical inference: Two interventions. Journal of Counseling and Development, 76, 74-81.

Clancy, S. (2005). Abducted: How people come to believe they were kidnapped by aliens. Cambridge, MA: Harvard University Press.

Cohen, A.S., Barlow, D.H., \& Blanchard, E.B. (1985). Psychophysiology of relaxation-associated panic attacks. Journal of Abnormal Psychology, 94, 96-101.

Cohen, P., \& Cohen, J. (1984). The clinician's illusion. Archives of General Psychiatry, 41, 1178-1182.

Coons, P.M. (1984). The differential diagnosis of multiple personality: A comprehensive review. Psychiatric Clinics of North America, 7, $51-57$.

Daldrup, R.J., Beutler, L.E., Engle, D., \& Greenberg, L.S. (1988). Focused expressive psychotherapy: Freeing the overcontrolled patient. New York: Guilford.

Dawes, R.M. (1994). House of cards: Psychology and psychotherapy built on myth. New York: Free Press.

Dineen, T. (2001). Manufacturing victims: What the psychotherapy industry is doing to people (3rd ed.). Montreal, ON, Canada: Robert Davies.

Dishion, T.J., \& Andrews, D.W. (1995). Preventing escalation in problem behaviors with high-risk young adolescents: Immediate and 1-year outcomes. Journal of Consulting and Clinical Psychology, 63, 538-548.
Dishion, T.J., Eddy, J.M., Haas, E., Li, F., \& Spracklen, K. (1997). Friendships and violent behavior during adolescence. Social Development, 6, 207-223.

Dishion, T.J., McCord, J., \& Poulin, F. (1999). When interventions harm: Peer groups and problem behavior. American Psychologist, $54,755-754$.

D’Silva, K.D., Duggan, C., \& McCarthy, L. (2004). Does treatment really make psychopaths worse? Journal of Personality Disorders, $18,163-177$.

8 charged in teen's boot camp death. (2006, November 28). CBS News [electronic version]. Retrieved January 20, 2007, from http:// www.cbsnews.com/stories/2006/11/28/national/main2211680. shtml.

Eisner, D.A. (2000). The death of psychotherapy: From Freud to alien abductions. Westport, CT: Praeger.

Feder, L., \& Wilson, D.B. (2005). A meta-analytic review of courtmandated batterer intervention programs: Can courts affect abusers' behavior? Journal of Experimental Criminology, 1, 239262.

Foa, E.B., Zoellner, L.A., Feeny, N.C., Hembree, E.A., \& AlvarezConrad, J. (2002). Does imaginal exposure exacerbate PTSD symptoms? Journal of Consulting and Clinical Psychology, 70, 1022-1028.

Fox, R.E. (1996). Charlatanism, scientism and psychology's social contract. American Psychologist, 51, 777-784.

Fox, R.E. (2000, Winter). The dark side of evidence-based treatment. Practitioner Focus [electronic version] Retrieved October 17, 2006, from http://www.apa.org/practice/pf/jan00/cappchair.html.

Frasure-Smith, N., Lesperance, F., Gravel, G., Masson, A., Juneau, M., \& Bourassa, M.G. (2002). Long-term survival differences among low-anxious, high-anxious and repressive copers enrolled in the Montreal heart attack readjustment trial. Psychosomatic Medicine, 64, 571-579.

Frasure-Smith, N., Lesperance, F., Prince, R.H., Verrier, P., Garber, R.A., Juneau, M., Wolfson, C., \& Bourassa, M.G. (1997). Randomized trial of home-based psychological nursing intervention for patients recovering from myocardial infarction. Lancet, 350, 473-479.

Freiheit, S.R., Vye, D., Swan, R., \& Cady, M. (2004). Cognitivebehavioral therapy for anxiety: Is dissemination working? Behavior Therapist, 27, 25-32.

Friedman, R.A. (2006, May 30). A case in point for the maxim "Do no harm." New York Times, D6.

Garfield, S. (1994). Research on client variables in psychotherapy. In A. Bergin \& S. Garfield (Eds.), Handbook of psychotherapy and behavior change (4th ed., pp. 190-228). New York: Wiley.

Ghaemi, S.N., \& Hsu, D.J. (2005). Evidence-based pharmacotherapy of bipolar disorder. In D.J. Stein, B. Lerer, \& S.M. Stahl (Eds.), Evidence-based pharmacotherapy (pp. 22-55). New York: Cambridge University Press.

Gilden, D. (1998, July/August). The search for more intelligent therapy. The body: The complete HIV/AIDS resource. Retrieved October 17, 2006, from http://www.thebody.com/gmhc/issues/ julaug98/haart.html.

Goisman, R.M., Warshaw, M.G., \& Keller, M.B. (1999). Psychosocial treatment prescriptions for generalized anxiety disorder, social phobia, and panic disorder, 1991-1996. American Journal of Psychiatry, 156, 1819-1821.

Harris, G.T., Rice, M.E., \& Cormier, C.A. (1994). Psychopaths: Is a therapeutic community therapeutic? Therapeutic Communities, 15, 283-299. 
Heide, F.J., \& Borkovec, T.D. (1984). Relaxation-induced anxiety: Mechanisms and theoretical implications. Behaviour Research and Therapy, 22, 1-12.

Herbert, J.D., Sharp, I.R., \& Gaudiano, B.A. (2002). Separating fact from fiction in the etiology and treatment of autism: A scientific review of the evidence. Scientific Review of Mental Health Practice, 1, 23-43.

Hunsley, J., \& DiGuilio, G. (2002). Dodo bird, phoenix, or urban legend? Scientific Review of Mental Health Practice, 1, 11-22.

Hunsley, J., \& Lee, C.M. (1995). The marital effects of individually oriented psychotherapy: Is there evidence for the deterioration hypothesis? Clinical Psychology Review, 15, 1-22.

Ilgen, M., \& Moos, R. (2005). Deterioration following alcohol-use disorder treatment in Project MATCH. Journal of Studies on Alcohol, 66, 517-525.

Jacobson, J.W., Mulick, J.A., \& Schwartz, A.A. (1995). A history of facilitated communication. American Psychologist, 50, 750-765.

Kluft, R.P. (1991). Clinical presentations of multiple personality disorder. Psychiatric Clinics of North America, 14, 605-629.

Lafferty, P., Beutler, L.E., \& Crago, M. (1989). Differences between more and less effective psychotherapists: A study of select therapist variables. Journal of Consulting and Clinical Psychology, 57, 76-80.

Lambert, M.J. (Ed). (2003). Bergin \& Garfield's handbook of psychotherapy and behavior change (5th ed.). New York: Wiley.

Lambert, M.J., \& Miller, M.J. (2001). Helping prospective patients avoid harmful psychotherapies. Contemporary Psychology, 46, 386-388.

Lambert, M.J., Whipple, J.L., Hawkins, E.J., Vermeersch, D.A., Nielsen, S.L., \& Smart, D.W. (2003). Is it time for clinicians to routinely track patient outcome? A meta-analysis. Clinical Psychology: Science and Practice, 10, 288-301.

Leventhal, L., \& Huynh, C. (1996). Directional decisions for two-tailed tests: Power, error rates, and sample size. Psychological Methods, $1,278-292$.

Levy, S.E., \& Hyman, S.L. (2005). Novel treatments for autism spectrum disorders. Mental Retardation and Developmental Disabilities Research Reviews, 11, 131-142.

Lewis, W.A., \& Bucher, A.M. (1992). Anger, catharsis, the reformulated frustration-aggression hypothesis, and health consequences. Psychotherapy, 29, 385-392.

Lilienfeld, S.O. (1997). The relation of anxiety sensitivity to higher and lower order personality dimensions: Implications for the etiology of panic attacks. Journal of Abnormal Psychology, 106, 539-544.

Lilienfeld, S.O. (1998). Pseudoscience in contemporary clinical psychology: What it is and what we can do about it. Clinical Psychologist, 51, 3-9.

Lilienfeld, S.O. (2002). The Scientific Review of Mental Health Practice. Our raison d'etre. Scientific Review of Mental Health Practice, $1,5-10$.

Lilienfeld, S.O., Fowler, K.A., Lohr, J.M., \& Lynn, S.J. (2005). Pseudoscience, nonscience, and nonsense in clinical psychology: Dangers and remedies. In R.H. Wright \& N.A. Cummings (Eds.), Destructive trends in mental health: The well-intentioned path to harm (pp. 187-218). New York: Routledge.

Lilienfeld, S.O., \& Lynn, S.J. (2003). Dissociative identity disorder: Multiple personalities, multiple controversies. In S.O. Lilienfeld, S.J. Lynn, \& J.M. Lohr (Eds.), Science and pseudoscience in clinical psychology (pp. 109-142). New York: Guilford.

Lilienfeld, S.O., Lynn, S.J., Kirsch, I., Chaves, J., Sarbin, T., Ganaway, G., \& Powell, R. (1999). Dissociative identity disorder and the sociocognitive model: Recalling the lessons of the past. Psychological Bulletin, 125, 507-523.

Lilienfeld, S.O., Lynn, S.J., \& Lohr, J.M. (Eds.). (2003). Science and pseudoscience in clinical psychology. New York: Guilford.

Lipsey, M.W. (1992). The effect of treatment on juvenile delinquents: Results from meta-analysis. In F. Loesel, D. Bender, \& T. Bliesener (Eds.), Psychology and law: International perspectives (pp. 131-143). Berlin, NY: Walter de Gruyter.

Littrell, J. (1998). Is the experience of painful emotion therapeutic? Clinical Psychology Review, 18, 71-102.

Litz, B.T., Gray, M.J., Bryant, R.A., \& Adler, A.B. (2002). Early intervention for trauma: Current status and future directions. Clinical Psychology: Science and Practice, 9, 112-134.

Loftus, E.F., \& Guyer, M. (2002). Who abused Jane Doe? The hazards of the single case history. Skeptical Inquirer, 26, 24-32.

Lohr, J.M., Hooke, W., Gist, R., \& Tolin, D.F. (2003). Novel and controversial treatments for trauma-related stress disorders. In S.O. Lilienfeld, S.J. Lynn, \& J.M. Lohr (Eds.), Science and pseudoscience in clinical psychology (pp. 243-272). New York: Guilford.

Lundeen, E. (2005, Fall). EBT and EVT: Can we please stop? Independent Practitioner, 25, 1-3.

Lynam, D.R., Milich, R., Zimmerman, R., Novak, S.P., Logan, T.K., Martin, C., Leukefeld, C., \& Clayton, R. (1999). Project DARE: No effects at 10-year follow-up. Journal of Consulting and Clinical Psychology, 67, 590-593.

Lynn, S.J., Lock, T., Loftus, E.F., Krackow, E., \& Lilienfeld, S.O. (2003). The remembrance of things past: Problematic memory recovery techniques in psychotherapy. In S.O. Lilienfeld, S.J. Lynn, \& J.M. Lohr (Eds.), Science and pseudoscience in clinical psychology (pp. 205-239). New York: Guilford.

Lynn, S.J., Martin, D.J., \& Frauman, D.C. (1996). Does hypnosis pose special risks for negative effects? International Journal of Clinical and Experimental Hypnosis, 44, 7-19.

MacKenzie, D.L., Gover, A.R., Armstrong, G.A., \& Mitchell, O. (2001, August). A national study comparing the environments of boot camps with traditional facilities for juvenile offenders (National Institute of Justice Research in Brief). Washington, DC: U.S. Department of Justice.

MacKenzie, D.L., Wilson, D.B., \& Kider, S.B. (2001). Effects of correctional boot camps on offending. Annals of the American Academy of Political and Social Science, 578, 126-143.

MacKillop, J., Lisman, S.A., Weinstein, A., \& Rosenbaum, D. (2003). Controversial treatments for alcoholism. In S.O. Lilienfeld, S.J. Lynn, \& J.M. Lohr (Eds.), Science and pseudoscience in clinical psychology (pp. 273-305). New York: Guilford Press.

Mai, F.M. (1995). Psychiatrists' attitudes to multiple personality disorder: A questionnaire study. Canadian Journal of Psychiatry, 40, 154-157.

March, J.S., Klee, B.J., \& Kremer, C.M.E. (2006). Treatment benefit and the risk of suicidality in multicenter, randomized, controlled trials of sertraline in children and adolescents. Journal of Child and Adolescent Psychopharmacology, 16, 91102.

Mash, E.J., \& Hunsley, J. (1993). Assessment considerations in the identification of failing psychotherapy: Bringing the negatives out of the darkroom. Psychological Assessment, 5, 292-301.

Masserman, T.H., \& Carmichael, H.T. (1938). Diagnosis and prognosis in psychiatry. Journal of Mental Science, 84, 893-946.

May, P., Tuma, H., \& Dixon, W. (1977). For better or for worse? Journal of Nervous and Mental Disease, 165, 231-239. 
Mayou, R.A., Ehlers, A., \& Hobbs, M. (2000). Psychological debriefing for road and traffic accident victims. British Journal of Psychiatry, 176, 589-593.

Mays, D.T., \& Franks, C.M. (1980). Getting worse: Psychotherapy or no treatment- the jury should still be out. Professional Psychology, $11,78-92$

McCord, J. (2003). Cures that harm: Unanticipated outcomes of crime prevention programs. Annals of the American Academy of Political and Social Science, 587, 16-30.

McNally, R.J., Bryant, R.A., \& Ehlers, A. (2003). Does early psychological intervention promote recovery from posttraumatic stress? Psychological Science in the Public Interest, 4, 45-79.

Meehl, P.E. (1993). Philosophy of science: Help or hindrance? Psychological Reports, 72, 707-733.

Mercer, J. (2002). Attachment therapy: A treatment without empirical support. Scientific Review of Mental Health Practice, 1, 105-112.

Mercer, J., Sarner, L., \& Rosa, L. (2003). Attachment therapy on trial. Westport, CT: Praeger.

Mohr, D.C. (1995). Negative outcome in psychotherapy: A critical review. Clinical Psychology: Science and Practice, 2, 1-27.

Mohr, D.C., Beutler, L.E., Shoham-Salomon, V., Bergan, J., Kaszniak, A.W., Yost, E.B., \& Engle, D. (1990). Identification of patients at risk for non-response and negative outcome in psychotherapy. Journal of Consulting and Clinical Psychology, 58, 622-628.

Moos, R. (2005). Iatrogenic effects of psychosocial interventions for substance use disorders: Prevalence, predictors, prevention. Addiction, 100, 595-604.

Mueser, K.T., \& Berenbaum, H. (1990). Psychodynamic treatment of schizophrenia: Is there a future? Psychological Medicine, 20, 253-262.

Neimeyer, R. (2000). Searching for the meaning of meaning: Grief therapy and the process of reconstruction. Death Studies, 24, $541-558$.

Norcross, J.C., Koocher, G.P., \& Garofalo, G.P. (2006). Discredited psychological treatments and tests: A Delphi poll. Professional Psychology: Research and Practice, 37, 515-522.

Ost, L.G. (1987). Applied relaxation: Description of a coping technique and review of controlled studies. Behaviour Research and Therapy, 25, 397-409.

Parent, D.G. (2003). Correctional boot camps: Lessons from a decade of research. Rockville, MD: U.S. Department of Justice.

Perls, F.S. (1969). Gestalt therapy verbatim. Moab, UT: Real People Press.

Petrosino, A., Turpin-Petrosino, C., \& Buehler, J. (2003). "Scared Straight" and other juvenile awareness programs for preventing juvenile delinquency. Annals of the American Academy of Political and Social Science, 589, 41-62.

Piper, A. (1997). Hoax and reality: The bizarre world of multiple personality disorder. Northvale, NJ: Jason Aronson.

Polusny, M.A., \& Folette, V.M. (1996). Remembering childhood sexual abuse: A national survey of psychologists' clinical practices, beliefs, and personal experiences. Professional Psychology: Research and Practice, 27, 41-52.

Poole, D.A., Lindsay, D.S., Memon, A., \& Bull, R. (1995). Psychotherapists' opinions, practices, and experiences with memories of incestuous abuse. Journal of Consulting and Clinical Psychology, $68,426-437$.

Powell, R.A., \& Gee, T.L. (1999). The effects of hypnosis on dissociative identity disorder: A reexamination of the evidence. Canadian Journal of Psychiatry, 44, 914-916.
Putnam, F.W. (1989). Diagnosis and treatment of multiple personality disorder. New York: Guilford.

Putnam, F.W., Guroff, J.J., Silberman, E.K., Barban, L., \& Post, R.M. (1986). The clinical phenomenology of multiple personality disorder: Review of 100 recent cases. Journal of Clinical Psychiatry, 47, 285-293.

Rhule, D.M. (2005). Take care to do no harm: Harmful interventions for youth problem behavior. Professional Psychology: Research and Practice, 36, 618-625.

Romanczyk, R.G., Arnstein, L., Soorya, L.V., \& Gillis, J. (2003). The myriad of controversial treatments for autism: A critical evaluation of efficacy. In S.O. Lilienfeld, S.J. Lynn, \& J.M. Lohr (Eds.), Science and pseudoscience in clinical psychology (pp. 363-398). New York: Guilford Press.

Rose, S., Bisson, J.I., \& Wessely, S. (2001). Psychological debriefing for preventing post traumatic stress disorder (PTSD) (Cochrane Review). In The Cochrane Library, 4. Oxford, England: Update Software.

Rosen, G.M. (1987). Self-help treatment books and the commercialization of psychotherapy. American Psychologist, 42, 46-51.

Rosen, G.M., \& Davison, G.C. (2003). Psychology should list empirically supported principles of change (ESPs) and not credentialed trademarked therapies or other treatment packages. Behavior Modification, 27, 300-312.

Rosenthal, R. (1979). The "file drawer problem" and tolerance for null results. Psychological Bulletin, 86, 638-641.

Ross, C.A. (1997). Dissociative identity disorder: Diagnosis, clinical features, and treatment of multiple personality. New York: Wiley.

Ross, C.A., Norton, G.R., \& Wozney, K. (1989). Multiple personality disorder: An analysis of 236 cases. Canadian Journal of Psychiatry, 34, 413-418.

Rubin, R., \& Rubin, R.A. (2005). Response to "Scientifically supported and unsupported interventions for childhood psychopathology: A summary." Pediatrics, 116, 289.

Schooler, J.W., Ambadar, Z., \& Bendiksen, M. (1997). A cognitive corroborative case study approach for investigating discovered memories of sexual abuse. In J.D. Read \& D.S. Lindsay (Eds.), Recollections of trauma: Scientific research and clinical practices (pp. 379-388). New York: Plenum.

Shapiro, D.A., \& Shapiro, D. (1982). Meta-analysis of comparative therapy outcome studies: A replication and refinement. Psychological Bulletin, 92, 581-604.

Sharp, I.R., \& Chapman, J.E. (2004). Antidepressants and increased suicidality: The media portrayal of the controversy. Scientific Review of Mental Health Practice, 3, 71-75.

Shipley, R.H., \& Boudewyns, P.A. (1980). Flooding and implosive therapy: Are they harmful? Behavior Therapy, 11, 503-508.

Sierra, F. (2005). Evidence-based medicine (EBM) in practice: Applying number needed to treat and number needed to harm. American Journal of Gastroenterology, 100, 1661-1663.

Sijbrandij, M., Olff, M., Reitsma, J.B., Carlier, I.V.E., \& Gersons, B.P.R. (2006). Emotional or educational debriefing after psychological trauma. British Journal of Psychiatry, 189, 150-155.

Singer, M., \& Lalich, J. (1996). Crazy therapies: What are they? How do they work? San Francisco: Jossey-Bass.

Skeem, J., Monahan, J., \& Mulvey, E. (2002). Psychopathy, treatment involvement, and subsequent violence among civil psychiatric patients. Law and Human Behavior, 26, 577-603.

Smith, M.L., Glass, G.V., \& Miller, T.I. (1980). The benefits of psychotherapy. Baltimore: Johns Hopkins University Press. 
Sommers, C.H., \& Satel, S. (2005). One nation under therapy: How the helping culture is eroding self-reliance. New York: St. Martin's Press.

Spanos, N.P. (1994). Multiple identity enactments and multiple personality disorder: A sociocognitive perspective. Psychological Bulletin, 116, 143-165.

Spanos, N.P., Weekes, J.R., \& Bertrand, L.D. (1985). Multiple personality: A social psychological perspective. Journal of Abnormal Psychology, 94, 362-376.

Stone, N., \& Borkovec, T.D. (1975). The paradoxical effect of brief CS exposure on an analogue phobic subject. Behaviour Research and Therapy, 13, 51-54.

Strupp, H.H., Hadley, S.W., \& Gomez-Schwartz, B. (1977). Psychotherapy for better or worse: The problem of negative effects. New York: Wiley.

Stuart, R.B. (1970). Trick or treatment: How and when psychotherapy fails. Champaign, IL: Research Press.

Tarrier, N., Pilgrim, H., Sommerfeld, C., Faragher, B., Reynolds, M., Graham, E., \& Barrowclough, C. (1999). A randomized trial of cognitive therapy and imaginal exposure in the treatment of chronic posttraumatic stress disorder. Journal of Consulting and Clinical Psychology, 67, 13-18.

Tavris, C. (2003). Mind games: Psychological warfare between therapists and scientists. Chronicle Review, February 28, B7-B9.

Tehrani, E., Krussel, J., Borg, L., \& Munk-Jorgensen, P. (1996). Dropping out of psychiatric treatment: A prospective study of a first-admission cohort. Acta Psychiatric Scandinavica, 94, 266271.

Tellegen, A., \& Atkinson, G. (1974). Openness to absorbing and selfaltering experiences ("absorption"), a trait related to hypnotic susceptibility. Journal of Abnormal Psychology, 83, 268-277.
Utah wilderness therapy deaths. (2003, July 13). Salt Lake Tribune [electronic version]. Retrieved October 17, 2006, from http:// www.sltrib.com/2003/jul/07132003/utah/75064.asp.

Wampold, B.E. (2001). The great psychotherapy debate: Models, methods, and findings. Hillsdale, NJ: Erlbaum.

Wampold, B.E., Mondin, G.W., Moody, M., Stich, F., Benson, K., \& Ahn, H. (1997). A meta-analysis of outcome studies comparing bona fide psychotherapies: Empirically, "All have won and all must have prizes. Psychological Bulletin, 122, 203-215.

Weiss, B., Caron, A., Ball, S., Tapp, J., Johnson, M., \& Weisz, J.R. (2005). Iatrogenic effects of group treatment for antisocial youth. Journal of Consulting and Clinical Psychology, 73, 1001-1008.

Weiss, R., Wilson, N.L., \& Whitemarsh, S.M. (2005). Evaluation of a voluntary, military-style residential treatment program for adolescents with academic and conduct problems. Journal of Clinical Child and Adolescent Psychology, 34, 692-705.

Werch, C.E., \& Owen, D. (2002). Iatrogenic effects of alcohol and drug prevention programs. Journal of Studies on Alcohol, 63, 581-590.

Westen, D., Novotny, C.M., \& Thompson-Brenner, H. (2004). The empirical status of empirically supported psychotherapies: Assumptions, findings, and reporting in controlled clinical trials. Psychological Bulletin, 130, 631-663.

Williams, S.L., Turner, S.M., \& Peer, D.F. (1985). Guided mastery and performance desensitization treatments for severe acrophobia. Journal of Consulting and Clinical Psychology, 53, 237-247.

Wilson, D.B., Gottfredson, D.C., \& Najaka, S.S. (2001). School-based prevention of problem-behaviors: A meta-analysis. Journal of Quantitative Criminology, 17, 247-272.

Wood, J.M., Garb, H.N., Lilienfeld, S.O., \& Nezworski, M.T. (2002). Clinical assessment. Annual Review of Psychology, 53, 519-543.

Yalom, I.D., \& Lieberman, M.A. (1971). A study of encounter group casualties. Archives of General Psychiatry, 25, 16-30. 